\section{A repetição em corpora históricos como índice de inabilidade em escrita*}

Repetition in historical corpora
as a written inability index

Huda da Silva SANTIAGO (UFBA) huda.santiago@hotmail.com

Zenaide de Oliveira Novais CARNEIRO (UEFS) zenaide.novais@gmail.com

Recebido em: 27 de jan. de 2018. Aceito em: 02 de jun. de 2018.

*Comunicação apresentada na Jornada Itinerante dos 40 anos do GELNE - Grupo de Estudos Linguísticos do Nordeste, que ocorreu em Aracaju-SE, no período de 7 a 9 de dezembro de 2017.

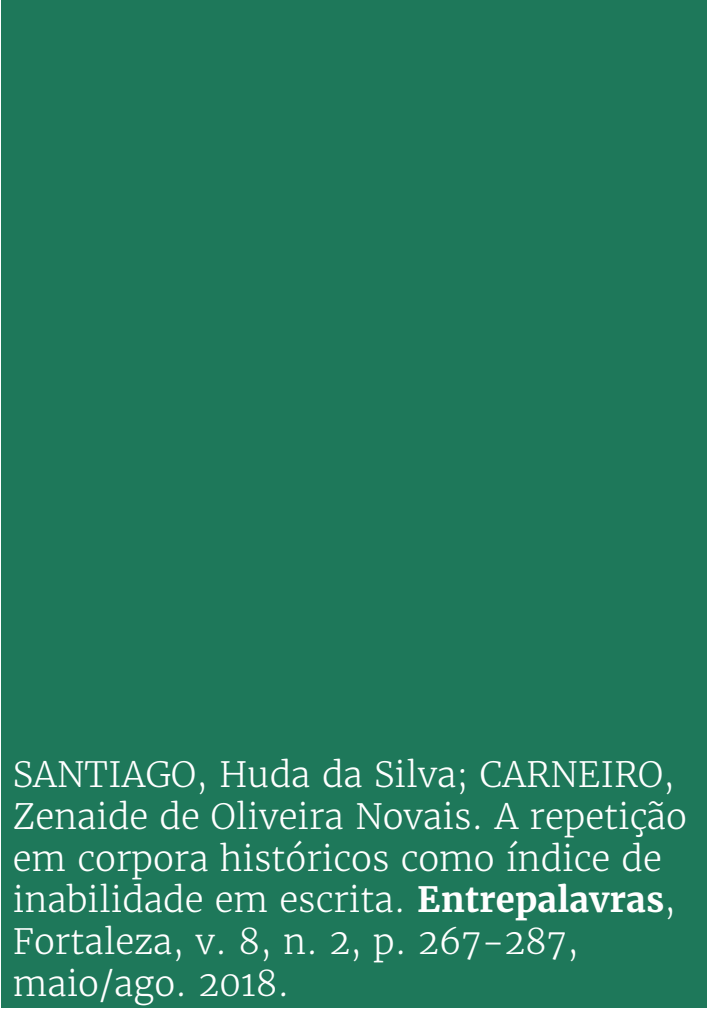

Resumo: Neste trabalho, o objetivo é discutir sobre a repetição de vocábulos na escrita por mãos inábeis, a partir de um corpus constituído por cartas pessoais de sertanejos baianos (19062000), redatores em fase inicial de aquisição da escrita, cuja edição está disponibilizada em Santiago (2011; 2012). A repetição é uma das dimensões da inabilidade em escrita alfabética proposta por Barbosa (2017), para a caracterização de corpora históricos. Nas cartas dos sertanejos, a presença dessa dimensão é mais um indício de que são textos espontâneos, sem planejamento e revisão, coincidindo, na escrita dos mais inábeis, com outras características, como os aspectos relacionados à escriptualidade (desconhecimento de convenções do padrão gráfico); a presença de uma escrita fonética e a pouca habilidade no plano motor, o que pode indicar um maior distanciamento aos modelos da escrita convencional. Em textos desse tipo, os redatores transferem para 0 registro escrito mecanismos de coesão e coerência comuns à oralidade, e os segmentos repetidos podem estar expressando funções semelhantes às da gramática da língua oral, como demonstram estudos como o de Dutra 
v. 8 (2)

267-287 mai/ago 2018

(2003), em dados de redações infantis, e o de Marcuschi (1996), com dados orais. Para melhor compreender algumas motivações que originaram as repetições pelos redatores das cartas, os exemplos são distribuídos de acordo com as possíveis funções que estejam manifestando, à luz das funções básicas já identificadas para textos orais: no plano textual, as relações de coesividade, e, no plano discursivo, as relações de compreensão, continuidade tópica, argumentatividade e interatividade.

Palavras-chave: Repetição. Mãos inábeis. Cartas pessoais.

Abstract: This paper aims to discuss the repetition of words in writing by unable hands, from a corpus consisting of data from Bahian sertanejos (1906-2000), writers in the initial writing acquisition phase, whose edition is available in Santiago (2011; 2012). Repetition is one of the inabilities in alphabetic writing dimensions proposed by Barbosa (2017), for a historical corpora characterization. In the letters of the sertanejos, the presence of this dimension is another indication that they are spontaneous texts, without planning and revision, coinciding in the writing of the poor writers with other characteristics, such as those related to escriptuality (lack of knowledge concerning to graphic standard conventions); the presence of a phonetic writing, and lesser motor skills, which may indicate a greater distance from the models of conventional writing. In texts like those, the writers convey on writing, the cohesion and coherence devices related to the speech, and the repetitive segments can be expressing similar functions to the oral language grammar, as Dutra (2003) has shown, through data from children's essays, and Marcuschi (1996) with oral data. To understand better some of the reasons that gave rise to the repetitions made by the letters' writers, the examples are distributed according to the possible functions they are communicating, to the light of basic functions identified for oral texts such as, cohesive relations in the text level, understanding, topical continuity, argumentative structure and interactivity relations in the discursive level.

Keywords: Repetition. Unable hands. Personal letters.

\section{Introdução}

A constituição e o tratamento de corpora diacrônicos com textos representativos da escrita cotidiana, vernacular, tem sido uma tarefa necessária e desafiadora, tanto no âmbito dos estudos sóciohistóricos do português brasileiro, como também dos estudos da História da Cultura Escrita, campo a que este trabalho se filia, de forma mais específica. O objetivo, neste estudo, é discutir sobre a repetição na escrita por mãos inábeis ${ }^{1}$, tendo por base um material formado por 91 cartas pessoais, do século XX, editadas por Santiago (2011; 2012). Essas cartas foram escritas por 43 sertanejos, nascidos no semiárido baiano, pouco escolarizados.

O reconhecimento de produtos gráficos de redatores como esses, em níveis iniciais de aquisição da escrita, pode ser feito, em corpora históricos, através da identificação de algumas marcas de inabilidade

${ }^{1}$ A expressão mão inábil foi usada por Marquilhas (2000) para designar os redatores de alguns manuscritos portugueses (século XVII), do arquivo da Inquisição, falantes estacionados em fase inicial de aquisição da escrita. 
em escrita alfabética². Nesse sentido, Afrânio Barbosa (2017) estabelece algumas "dimensões de inabilidade" para a caracterização dos textos, considerando a possibilidade de um contínuo, uma gradiência, em que a presença de algumas marcas, de modo independente ou combinado, indica uma mão mais inábil ou menos inábil. Essa possibilidade de distribuição é uma tentativa de colaboração para o tratamento mais adequado da caracterização dos redatores nos corpora linguísticos, hoje polarizados entre hábeis e inábeis, sem maiores diferenciações intermediárias. As nove dimensões de inabilidade propostas pelo autor são:

1) da escriptualidade - os grafismos;

2) da escrita fonética - índices grafofonéticos;

3) da pontuação;

4) lexical - a repetição de vocábulos;

5) lexical - a dificuldade de riqueza na variação e precisão no léxico;

6) dos aspectos sintáticos;

7) das tendências discursivas;

8) da habilidade motora - níveis supragráfico e paleográfico, e 9) da segmentação gráfica - hipersegmentação e hipossegmentação.

Neste texto, a ênfase é para a descrição dos dados das cartas dos sertanejos referentes à dimensão 4, que, aqui, não se considera propriamente como "lexical", mas, sim, como textual, já que é consequência da transposição, para a escrita, de um aspecto textual do registro oral. De acordo com Barbosa (2017, p. 25), a repetição de vocábulos em sequência na mesma sentença ou em sentenças subsequentes é um "sinal objetivo ligado em direto à oralidade" e pode ser o reflexo "da busca de uma riqueza lexical não apreendida no contato com textos modelares da cultura escrita de sua época". Essa repetição não é aquela com os "termos lado a lado", ou seja, não são os lapsos próprios da cópia em mais de uma via³.

Em algumas cartas, a presença excessiva da repetição, com características próximas às dos usos da oralidade, é mais um indício de que são textos espontâneos, sem planejamento e revisão. O que se tem

2 Este trabalho, cujos dados são extraídos da dissertação de mestrado de Santiago (2012), integra a pesquisa atual de doutorado da mesma pesquisadora.

3 Telles e Lose (2010, p. 113) incluem essas repetições (com os "termos lado a lado") entre os "erros óbvios (ou lapsus calami)" que podem ser motivados a partir da escripta do documento. 
v. $8(2)$

267-287

mai/ago 2018

é a primeira versão de uma escrita ao "calor da hora". Considerando a possibilidade de um contínuo, essa dimensão coincide, na escrita dos mais inábeis, com outras características, como os aspectos relacionados à escriptualidade (desconhecimento de convenções do padrão gráfico, como a dificuldade em grafar sílabas complexas com as consoantes líquidas /r/ ou /l/); a presença de uma escrita fonética, e a pouca habilidade no plano motor e na organização gráfica do texto, o que pode indicar um maior distanciamento aos modelos da escrita convencional.

As repetições são descritas, aqui, tendo por base o estudo de Marcuschi (1996), em que, através de uma abordagem funcional, esse autor identifica funções básicas para as repetições da oralidade: no plano da composição do texto, há as relações de coesividade; e, no plano discursivo, as repetições colaboram para compreensão, continuidade tópica, argumentatividade e interatividade.

\section{Alguns estudos sobre repetição}

Na escrita, a presença da repetição - com outras funções e em menor proporção que na modalidade oral - é uma estratégia que pode contribuir para a textualidade (ANTUNES, 2005) ${ }^{4}$. Na oralidade, segundo Marcuschi (1996, p. 97), essa é uma das estratégias de formulação textual mais presentes, e consiste na "[...] produção de segmentos discursivos idênticos ou semelhantes duas ou mais vezes no âmbito de um mesmo evento comunicativo". O "segmento discursivo" designa, para o autor, qualquer produção linguística da oralidade, seja um segmento fonológico, uma unidade lexical, um sintagma ou uma oração. Sob esse ponto de vista, de acordo com o segmento repetido, as repetições podem ser: fonológicas, morfológicas, lexicais, sintagmáticas e oracionais.

A análise das funções da repetição na oralidade permite, de acordo com o autor, constatar que o texto falado progride e se constitui localmente, segundo o autor, on-line. Para ele, a presença da repetição na superfície do texto falado é alta, já que, em média, a cada cinco palavras, uma é repetida, enquanto que "[...] na escrita, com a possibilidade de revisão e editoração, com apagamentos sucessivos, só se obtém a versão final, diminuindo a presença da repetição" (MARCUSCHI, 1996, p. 95). Nesse mesmo sentido, Fávero et al. (2012, p. 34), ao tratar dos fatores de coesão e coerência na fala, afirmam que "[...] a alta incidência de

${ }^{4}$ A repetição é considerada por Antunes (2005, p. 51) como um procedimento de uma das relações textuais de coesão, a reiteração. Como procedimento coesivo, a repetição envolve os seguintes recursos: paráfrase, paralelismo e repetição propriamente dita. 
repetições no texto falado é perceptível com facilidade e favorece a coesão, além de contribuir para a organização tópica".

Em textos escritos em que predomina a espontaneidade, sem um planejamento global, refletindo condições de produção ligadas ao tempo real, os segmentos repetidos podem expressar funções semelhantes àquelas da fala. Isso pode ser notado na escrita de indivíduos em fase de aquisição do código escrito, seja em textos infantis, como demonstra o trabalho de Dutra (2003), com redações escolares, ou em textos históricos, como exemplifica Marquilhas (2004), a partir de dados de cartas populares do século XVII.

Dutra (2003) analisa a repetição, incluída, pela autora, entre os princípios de organização da gramática da língua oral, como um reflexo da tentativa da criança em criar na escrita o mesmo dinamismo, a mesma fluidez e o mesmo ritmo, ou seja, as mesmas relações que, inconscientemente, aprendeu a desenvolver para o registro oral, por ter dificuldades em perceber que as regras de concatenação que operam no discurso escrito são diferentes das que operam no discurso oral. Nas redações infantis, a repetição pode, então, ter sido usada para realçar, enfatizar, ou mesmo retomar o curso dos eventos numa história, por exemplo.

Em textos históricos, esse aspecto ainda não é muito explorado, principalmente quando se trata de observar a sua relação com a questão da inabilidade em escrita. Marquilhas (2004), ao comentar que cartas populares e familiares, em contraposição às literárias e institucionais, são o testemunho linguístico mais próximo que se tem da língua oral, apresenta um exemplo de repetição de formas lexicais em cartas do século XVII, do arquivo da Inquisição portuguesa:

(o1) "Sua mãe [e] irmã, consoantes nestas cousas, que todas três trato nesta cousa". (Carta V, MARQUILHAS, 2004, p. 723).

Esse exemplo, ao lado de exemplos de outros fenômenos 5 , é apresentado pela pesquisadora para demonstrar que, em amostras desse tipo, podem-se encontrar todos os fenômenos que hoje se observam ao nível do léxico, da sintaxe e do discurso oral.

\footnotetext{
${ }^{5}$ Além da repetição de formas lexicais, Marquilhas (2004, p. 723) cita e exemplifica os seguintes fenômenos: os processos de redobro, sobretudo o da recomplementação; as constantes focalizações e topicalizações; a modalidade; o recurso às interjeições, aos bordões, à deixis textual com aparente abuso de pronomes catafóricos, à deixis pessoal pela repetição da forma de tratamento do destinatário do discurso e ao tratamento informal.
} 
v. 8 (2)

267-287 mai/ago 2018

A seguir, serão descritos alguns casos de repetição, identificados no corpus, à luz das funções básicas estabelecidas por Marcuschi (1996) para os textos orais, no sentido de melhor compreender algumas motivações para o uso desse fenômeno pelos redatores.

\section{A repetição nas cartas dos sertanejos}

De modo geral, os casos de repetição no corpus aparecem bem distribuídos em cartas de 26 dos redatores: para cada um deles há uma média de um a três casos (exceção de $\mathrm{AFS}^{6}$, com 11 dados, distribuídos em 11 cartas, e JMS, com 7 dados, em apenas uma carta, das três que escreveu). Acrescido a outras dimensões, esse é um aspecto que contribui para caracterizar uma maior inabilidade; mas não é tão decisivo, já que há textos, como a carta de JS, redator que é considerado como mais inábil, pela quantidade de dados em outras dimensões - especialmente em relação aos dados referentes à escriptualidade - em que não foram identificadas muitas repetições. No Quadro 1, comparam-se alguns dados desse redator com os de JMS, cuja carta apresenta muitas repetições, mas, pela pouca presença de irregularidades na dimensão da escriptualidade (como os desvios na grafia de sílabas complexas com $\mathrm{o}<\mathrm{r}>$ ) e da habilidade motora, é considerado como parcialmente inábil.

Quadro 1 - Exemplos de níveis de inabilidade

\begin{tabular}{|c|c|c|}
\hline \multirow{3}{*}{ Dimensões de inabilidade } & Inabilidade máxima & Inabilidade parcial \\
\hline & \multicolumn{2}{|c|}{ Redatores/quantidade de ocorrências } \\
\hline & $\begin{array}{c}\text { JS } \\
\text { (202 palavras - } 1 \text { carta) }\end{array}$ & $\begin{array}{c}\text { JMS } \\
\begin{array}{c}\text { (1204 palavras - } \\
\text { cartas) }\end{array}\end{array}$ \\
\hline Escriptualidade & $34,2 \%$ & $0,9 \%$ \\
\hline Escrita fonética & $19,8 \%$ & $23 \%$ \\
\hline $\begin{array}{l}\text { Aspectos no plano da } \\
\text { habilidade motora }\end{array}$ & $\begin{array}{c}\text { Ausência de cursus, } \\
\text { irregularidade da } \\
\text { empaginação e letras } \\
\text { monolíticas }\end{array}$ & -- \\
\hline Repetição & 2 casos & $\begin{array}{c}7 \text { casos } \\
\text { (concentrados } \\
\text { apenas na carta } 66 \\
-499 \text { palavras) }\end{array}$ \\
\hline
\end{tabular}

Fonte: elaborado pela autora.

\footnotetext{
${ }^{6}$ Os redatores são identificados, ao longo do texto, pelas mesmas siglas usadas em Santiago (2012). E a identificação dos exemplos se dá com a indicação da sigla do remetente, seguida do número da carta em que a ocorrência está localizada, conforme numeração usada na edição semidiplomática (SANTIAGO, 2012).
} 
Nas Figuras 1 e 2, a seguir, trechos da edição fac-similar e semidiplomática7 das cartas de JMS e JS, respectivamente:

Figura 1- Exemplo de trecho de carta com muitos dados de repetição

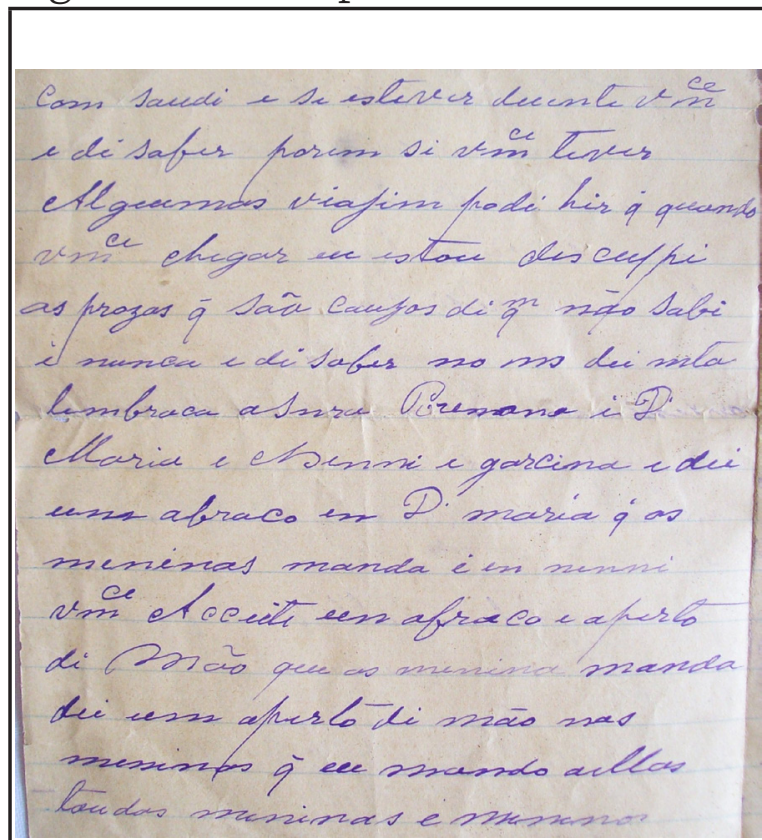
JMS - Carta 66 [fol. 2r]

com saudi e se estiver duente vosmecel e di saber porem si vosmece tiver| Algumas viajim podi hir que quandol vosmece chegar eu estou desculpil as prozas que são cauzos di quem não sabil i nunca e di saber no mais dei muital lembraca asenhora Rumana i Donal Maria e Nenni e garcina e deil um abraço em Dona maria que as| meninas manda i em nennil vosmece Acceite um abraco e apertol di mão que as menina manda| dei um aperto di mão nas| meninas que eu mando aellas| toudas meninas $\mathrm{e}$ meninos|

Fonte: Santiago (2012)

Figura 2 - Exemplo de trecho de carta com pouca repetição

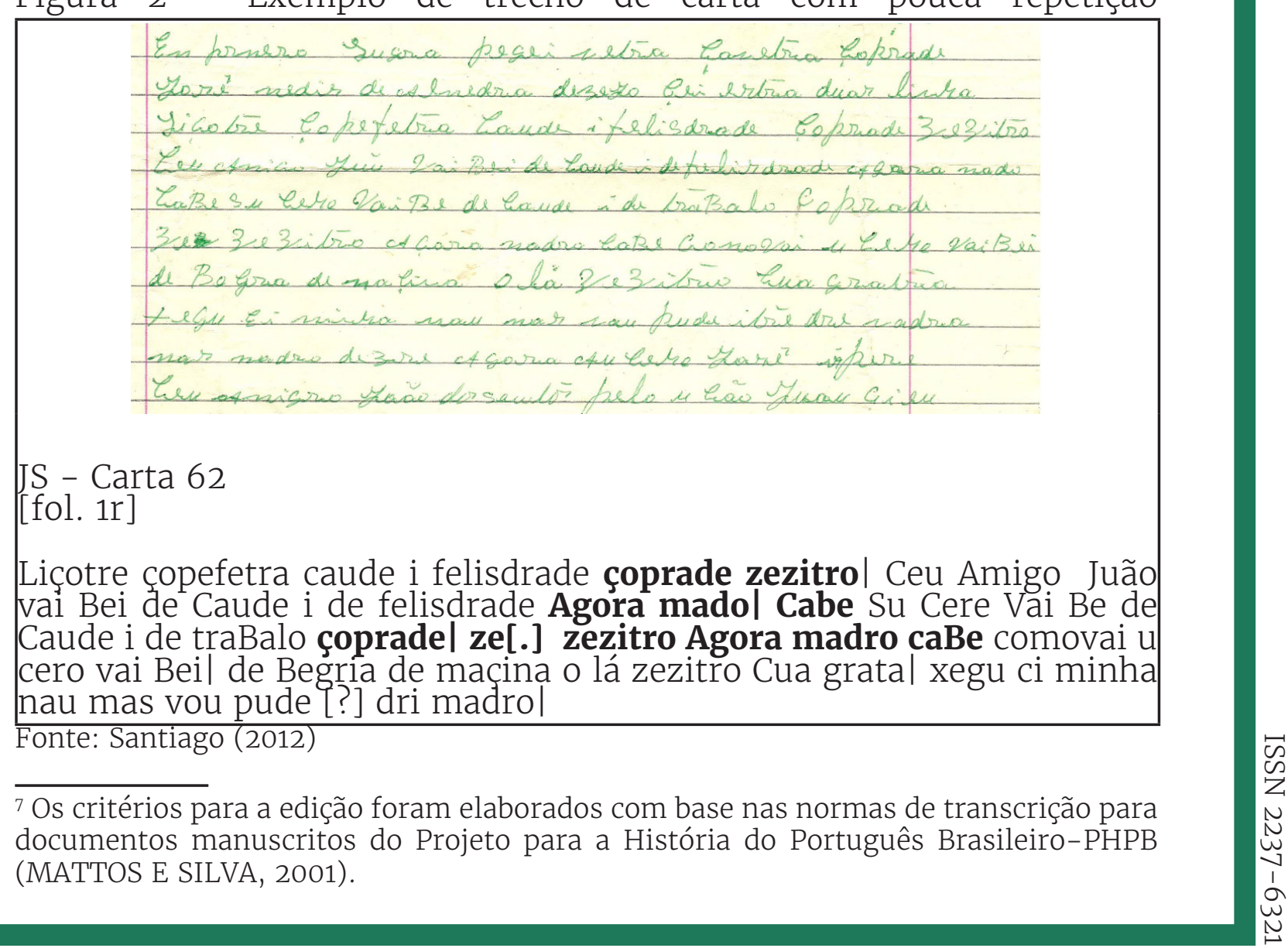


v. 8 (2)

267-287

mai/ago 2018
No trecho ilustrado na Figura 1, uma carta datada de 1906, com uma boa aparência dos aspectos caligráficos (habilidade motora), identifica-se a repetição de vosmece (4 vezes), palavra que aparece abreviada; da expressão que as menina manda (2 vezes), de modo que a palavra menina/s é registrada 4 vezes; da expressão aperto di mão (2 vezes) - na continuação da carta, no verso desse fólio, constam mais dois casos de um aperto di mão -, e a repetição do verbo dar (dei). No entanto, na Figura 2, o trecho de uma carta escrita no início da segunda metade do século XX (não é datada, mas foi possível fazer essa inferência pelas demais correspondências recebidas pelo mesmo destinatário), são poucas as repetições: çoprade zezitro (por compadre Zezito) e Agora mado Cabe (por agora mando saber). Além de se notar uma dificuldade motora, há um alto índice de grafias irregulares, envolvendo, principalmente, inversão e acréscimo de $\langle\mathrm{r}\rangle$, como em çopefetra (por com perfeita) e felisdrade (por felicidade).

A repetição não é, portanto, uma dimensão independente e só combinada a outras irá ajudar na caracterização do nível de familiaridade dos redatores com o código escrito, assim como as que se referem à pontuação e à segmentação gráfica.

Quanto à distribuição dos exemplos de itens repetidos, de acordo com as possíveis funções que estejam manifestando, é preciso ressaltar que isso não é feito de forma rígida, pois uma ocorrência que pode estar sendo motivada pela intenção de estabelecer a coesividade, pode também estar expressando funções relacionadas a aspectos discursivos, como facilitar a compreensão ou a continuidade tópica.

Coesividade

Do ponto de vista da organização textual, a repetição colabora para a coesividade e é usada, principalmente, para promover a sequenciação e o encadeamento dos enunciados. Uma estratégia comum de coesão sequencial, segundoMarcuschi (1996), é o princípio da listagem, que, além de ser uma estratégia para a "conexão inter-frástica", cria um ritmo especial na interação e possibilita maior envolvimento. As listas são "[...] facilmente identificadas como paralelismos sintáticos, geralmente com variações lexicais e morfológicas e manutenção de uma estrutura nuclear" (MARCUSCHI, 1996, p. 107). Os exemplos seguintes ilustram encadeamentos do texto por meio de listagens: 
(02) [...] lembrança para voce i lembrança esmerindal i lembrança Ogusto i lembrança Pedrinho lembrança| luizinha que é para esmerinda dar a ela i 1 apretol di mão.. lembranca a Anna i angelica mandal lembranca para esmerinda i todos.. i Filomena emvial lembrança para esmerinda i todos $\mid[\ldots]$ (SFS-40)

(03) $[. .$.$] vou treminar enviando <个lembranças >$ para voce i tambem| muita lembrança $<\uparrow a>$ Pitanga lêmbrança Ana i) muita lembrança Augusto i tambem al Pedirnho [...] (APS-43)

(04) [...] Aceite lembarnça minha i de todos meus| enviando lembarnça a pitanga i a anal e a Augusto [...] (FPS-47)

(05) [...]Acceite um abraco e apertol di mão que as menina mandal dei um aperto di mão nasl meninas que eu mando aellas| toudas meninas e meninos no mais viri e $\mathrm{co}<\uparrow n>$ tinuil Agora Comadre vosmece dei muitallembranca i um aperto di mão| A compadri Antonio que eu mandol e vosmece Acceiti vizita i um abracol [.] e um aperto di mão di sual comadre [...] (JMS-66)

(06) [...] Amiga aceiti muita lembranca di qui minha mai mandal i 1 abarco aceiti lembranca qui maria i garcina i nenen| li manda irabarco $i$ aceiti as minha lenbracal $\mathbf{1}$ abraco i muita saudadi des ta di minuta amigal [...] (FP78)

(07) [...] Sim Nerado mande mi dize quantol qusta um dia de um tarbalhador e $\mathbf{1}$ | saco de farinha e $\mathbf{1}$ saco $<\uparrow$ de $>$ feijão e 1| saco de milho e se a vaca barca jál pario [...] (ROM-73)

Com exceção do último exemplo citado, que apresenta uma lista de produtos, os demais expressam listas de saudações enviadas, seja aos destinatários ou a outras pessoas; é uma forma de sustentar o tópico, como no exemplo (02), de SFS, em que a palavra lembrança aparece oito vezes em um trecho de pequena extensão. Muitas vezes a repetição é usada por causa da dificuldade do redator em utilizar 
v. 8 (2)

267-287 mai/ago 2018

algumas estratégias convencionais de coesão textual, como os elementos anafóricos e os conectivos. Assim, nos trechos seguintes, há a repetição dos itens lexicais e não a sua pronominalização:

(08) [...] sim conpadil eu estou farzenno| tencão di li mandar| Dinheiro pa u sinhorl f farzêr A miha cazal que eu quero enboral mais eu solvou condol miha caza liver pontal[...] (AFS-18)

(09) [...] Zezito quando você vi traga um/ retrato da lapinha para a gente ve quel nunca vi[.] e Deseijo vir Sua lapinha| [...] (AHC-56)

Há uma predominância de casos de repetições envolvendo os nomes, mas há, também, muitas ocorrências envolvendo os verbos. No exemplo (10), há a recorrência ao verbo ser para sequenciar os fatos narrados no tempo pretérito, já no caso do (11), a repetição do verbo ir deve-se ao seu uso como auxiliar, marcando o futuro:

(10) Zezete voce teve novidade| e não mandou mi dizer| foi você e Neraudo que foi ol padrinho de cazamento de Zifirinol si foi manda mi dizer. I Zezete voçe mandou mi perguntar| si eu já tinha mi Operado dais| varis mais não foi a Operei para não terl mais filho ti asegura que eu já mi al seguri Olha minha filha foil emternada 8 dia mais ja tar boal [...] (ZLS-70)

(11) [...] tem dia que pençol que vou ficar paralitical mas só Deus sabel estou pençando de procurar| um ortopedista em Riachãol tem um que trabalha todal quarta mas não sei sel trabalha por todos convenhos| vou me informar melhol e vou, procurar me cuidar| pois já faz tempo quel estou centindo e nuncal foi ao medico Olhel aqui vou te mandar| o numero do telefonel de Carmelital 9961-5406 é celular| Olhe Lena vou terminar| com muita saudade [...] (IZA-87)

A repetição foi usada para correção e também marcando certa hesitação, como demonstram, respectivamente, os trechos exemplificados em (12) e em (13): 
(12) [...] Jose Ogusto Jose romaro que eu e totol e Liza e elsione e Jose Luis mada| [.] manda mi dizer si tivero mutol mantinentol [...] (ZLS-70)

(13) [... Z Zizete Roma manda lhi pedir 1/ favor e que que [.] voçe fasa que que | conpre n 6 vela e senda no per do santol in tesão da alma de Miro Olhe nãol esquesa [...] (ROM-73)

Compreensão

As repetições podem colaborar para tornar as sequências mais compreensíveis, facilitando o entendimento do que se quer dizer ao interlocutor, seja no sentido de intensificação ou de maior esclarecimento. Observa-se, nos exemplos, a tentativa de atribuir certa ênfase ao item repetido, intensificando-o:

(14) [...] tenha fêrz ni mim que eu tenhol ni Deus| Sim tenhor Fers | ni Deus i mil mim| boti umma bençal ni meu Pitico i ni Dês| [...] (AFS-15)

(15) [...] eul estou gananno 305 mil por meis mas| o menno conpadi u sinhor podi pegal na mia caza ir podi [.] podi| farzer s sin conpadi [.] [.] eul não mando Diheiro mas podi farzer| $[\ldots]($ AFS-11)

(16) [... eu mais todos meu Voul indo- eu Vou sempre andanol sempre duentada commadrel Aseite uma Bensa de Raquel [...] $(\mathrm{MC}-50)$

(17) [... diga al ela que e com muita Saudade da quil e com Saudade que [.] recordo meus pasado el com vontade de chega os relembralo.I (AHC-55)

(18) [... Esta duas linha solmentil par lidar a mihas notissa nu mimo pempol salber da sua i di toudo da qui siml Compadi p pitanga u purqui u sinhorl min esqrevi par mim serra que eu soul tom rui eu solu u memo Aqueri minno Amigos| eu mando lir pidir que min esqreva par min| eu quero salber A sua notisa i di toudo dar quil lenbansa $A$ 
v. $8(2)$

267-287

mai/ago 2018

minha Commadi Almerinda i ul minino i a toudo dar qui sim Compadi min / mandi Dizer Commo vai Aqui bonpansa eu querol Salber di tudo dar qui [...] (AFS-4)

(19) [...] mais viva Deus $\mid$ eu ei de alcançar a felisidade| algum dia com fé em Deus el nossa Senhora eu me comformol com as ordem de Deus Deus viol que não era tempo de vim buscar| nem um nem outro [...] (MDC-84)

(20) [...] fis ol pusive para viver [.] jontol ate o dia que Deus vimhesel buscar eu ou ele. mas foi nada| tudo que eu fazia era nada| nomca vi um coração tãol imgrato naquela forma. [...] (MDC-84)

Marcurschi (1996, p. 113) informa que os casos de intensificação podem estar obedecendo ao "princípio de iconicidade", em que a um maior volume de linguagem idêntica corresponde um maior volume de informação. Segundo Dutra (2003, p. 44), que apresenta a iconicidade como um dos princípios fundamentais da gramática da língua oral, esse "[...] é um princípio de organização gramatical que tenta refletir o mais diretamente possível, como uma fotografia reflete o objeto fotografado, um certo estado de coisas no mundo real que experienciamos". Os itens lexicais repetidos nos trechos exemplificados são, portanto, icônicos, à medida que tentam traduzir os desejos, estados e sentimentos de modo mais imediato, tornando-os mais transparentes e facilitando a compreensão.

A necessidade de um maior esclarecimento das informações pode ter motivado as repetições a seguir:

(21) [...] u sinhor| farsa A miha cazal que eu vou sir Deus| quizer Derta que eul mando u Dinheiro| ou sirnão condo eul for eu leivol u Dinheiro| nu dia 25 di Agostol eu vou mandar| Dinheiro Par u sinhol conpar milho il tonbem farzer A minhal cazal [...] (AFS-14)

(22) [...] eu nuca tive votadi de temina com vocel oli Se voce gue termina e distui u nocu- la tomi esta tiludi Se ceu pai não gel gi [.] voce conciga o nocu Romaci e vocel ge [.] temina com migo [...] (JMA-64) 
(23) [...] Elena eu lhil pergunto se já chigou a pozetadorial de Esmerado porque a que estel meis chegou de muita jente e eul espero em Deus que a dele tenhal xegado tambem que para mi seral alegria Olhe Elena segue estes 50 mil se não tever xegado | a pozetadoria dele vocé da a ele el se tever xegado vocé com estel dinhero mi conpre 1 Toalha del meza de Renda [...] (ASC-63)

(24) [...] Parece que foi robado; mas| peguei sabendo que voces| não queria; estava perto dol corredor perto de Albertinal quando ela morava.I [...] (MMO-76)

(25) [...] eu grite pela a Seinora que mi Valel| mais mai eu esto bem não si precoupel que eu esto com [?] e eli Nãol deixa falta Nada para mi eu tombem/ esto trabalhado com Miranda [...] (VAN-86)

Vale ressaltar que as repetições não garantem que os referentes sejam idênticos. Exemplos disso são notados nos trechos em (26) e em (27):

(26) [...] vose manduo dizer quel Datiu tinha vendido a galinha| Olhe a galinha não e dele iul Frango branco i outra galinha| tabem não e dele mande dizer| como vai a noca galinha| Di rasa com os pintinhos| [...] (GOR-28)

(27) [...] comta os meus pascado para ver [.] sil pur meio dessa eu posso colher as suas | noticias que as minhas noticias ja vail i lhi pesco as minhas desculpa [...] (JMS-66)

Não é apenas a uma galinha que o item lexical repetido na carta de GOR se refere, são diferentes referentes, na verdade, três galinhas; assim como notícias, na carta de JMS, pois primeiro referemse às notícias do destinatário e depois às do remetente.

Continuidade tópica

Algumas ocorrências de repetição podem estar refletindo a necessidade de dar continuidade ao texto, seja com a intenção de introduzir, reintroduzir, manter ou delimitar tópicos (MARCUSCHI, 
v. 8 (2)

267-287 mai/ago 2018
1996). A repetição da palavra diga, no exemplo (28), situa o interlocutor, marcando a introdução de um novo pedido/ordem ao destinatário:

(28) [...] Diga a compadre ogusto que eu ja escrivil A ele i ele não mi mandou dizer nada diga al Ele que mande me dizer si ja cazou| Diga aele que dexe pra quando eu xegar| Compadre diga a Juão nasimento| que brazilha e iluzão i so vem quem nãol sabe [...] (GOR-29)

O redator faz diferentes solicitações, enviando recados para terceiros e introduzindo-os com o verbo diga. Construção semelhante foi usada no exemplo (29), em que o redator envia vários versos para outras pessoas. De início, repete a oração vai um verso e no fim há a elisão do verbo, com a repetição do sintagma nominal um verso:

(29) [...] vai um verço| ci eu fosse um belol pascaro [.] que podesse avoar| eu já cei que eu estaval alegri todu dia eu estaval lar| vai um vesso pra Hildebrandol quando eu alembro do meul irmão que saudade quel mi dar quando eu fuil eu ti levei quando eul vin pra ti buscar| um vesso [.] pra u meu pail quando u pai chama u filhol mais que ele atenderal ele dis vamos meu filhol vamos pra rossol trabalhal (ACO-44)

Na carta de BMO, a repetição da palavra conversa, que é mencionada três vezes, colabora para dar continuidade ao tópico em questão:

(30) elena aquela converça com seu nomil ja acabou olha as mesma converçal saiu aqui com meu nomi não voul conta porque não tenho tempo porquel quando jose falou de ir eu alembreil di te escrever esta duas linha so paral te fala que eu fique um mui tristil quando eu subi di converça que eul não posso aseita elena [...] (BMO-90)

Argumentatividade

As repetições, sobretudo as de orações, apresentam um papel importante na condução da argumentação, de acordo com Marcuschi (1996, 
p. 118), e "servem como estratégia para reafirmar, contrastar ou contestar argumentos". Nos dados, nota-se que, com os raros casos de repetições oracionais, o objetivo principal é a reafirmação de um argumento:

(31) Eu li escrevo para li pedi Comadrel Doralice para ficar mais eu ate nol dia 2 a te pelo amor de Deus quel eu tenho tanto trabalho que eu não| Poso fazer olhe tia não mi falter| e para ela me ajudar eu arumar| A casa que eu não poso fazer sol Ai mãe manda li dizer que ela estar| Andano doemte não estar podemo mil Ajudar nos trabalho e eu não poso| Fazer sozinha [...] (ICO-48)

(32) [... Tenho uma posi de terral de Antonio no terreno dil sucavão eu quro a preferen|ça não Venda a nigem| sem mi uver eu querol Ser u comprador não| Venda a nigem sem mil Ver mas nadal [...] (JSS-88)

No exemplo (31), em que é expresso um pedido, a oração eu nao poso fazer é repetida na tentativa de convencer a destinatária a atender sua solicitação. Além disso, como o pedido está centrado no seu problema pessoal, a remetente focaliza a primeira pessoa, de modo que o pronome eu aparece sete vezes e o mi/me, três vezes. Também para reafirmar um pedido, no exemplo (32), o redator não constrói uma estratégia de argumentação muito forte, mas repete a oração não venda a nigem sem mi ver, provavelmente, para convencer o leitor a realizar o que deseja.

Interatividade

Se, no plano discursivo da oralidade, a repetição contribui para o envolvimento interpessoal, nas cartas, gênero escrito que tem por base justamente as relações interpessoais, os remetentes podem ter usado esse recurso como estratégia para manter tal envolvimento. A repetição da forma de tratamento do destinatário do discurso, frequente no corpus, pode ser um indício disso ${ }^{8}$. Em algumas cartas, a repetição manifesta um teor vocativo, uma tentativa de atrair a atenção do leitor, ratificando o papel do ouvinte.

8 Esse fenômeno, "a dêixis pessoal pela repetição da forma de tratamento do destinatário do discurso", foi citado por Marquilhas (2004, p. 723), como uma das características das cartas populares e familiares. 
V. 8 (2)

$267-287$

mai/ago 2018
(33) pitanga como vai u sinhor| i todos ceu eu vim nu riachão| mais não pudi vim Atel Aquil muita lenbança A todos da nobil cazal A [.] compadi pitanga u sinhor| receiba um ricibo nul cartorio di donna Forizete u cartoriol fica na rua da igerjal u sinhor porqure i receiba il que jar pargei 20 mill i u sinhor min mandi por portador | certol firca $u$ sinhor encaregado estel recibo [...] (AFS-22)

(34) jetudis firgou entega Au simhor.I i A compadi farsa um tudo purmin detas que nois| ten tempo par Acerta tudo $\mathrm{s}$ u simhor min esqeival i mandi dizer com vai di s saudi u simho i toudol [...] (AFS-23)

(35) [...] espero que esteha tudor bem com al siorra porque eu não teno noticial da Seiora [.] tudos esta bem i madil dese com esta a Seiora oliha mãel eu tive om probema [...] (VAN-86)

(36) [...] não lhi escrevo porquer| não tenho por quem mandar| mais agora eu rezovir escrever| para a senhora e pessor quel a senhora mim respotel [...] (LM-75)

(37) [...] tirite de cabe o gi ta acotecenol com voce gerida mu bei eu ti amol eu sigo com u mesim cario para vocel tudo so depede de voce eu não esitou til enganano ja não cei o gi pocu Fazer| com tudo icol Eu esitou muito nevozo não teio gupa del gosta tanto de voce meu Deus cera gil ceu pai nuca vai mi compiender| eu nuca tive votadi de temina com vocel oli Se voce gue termina e distui u noculla tomi esta tiludi Se ceu pai não gel gi [.] voce conciga o nocu Romaci e voce| ge [.] temina com migo peri e mi respondal gi eu não temino com voci [.] meu beil eu co não micaco cmo voci Se voci nãol gize com liliaca cua vai um Bejo [...] (JMA-64)

(38) [...] eu não mi esquecol di vosmece tanto vosmece si lembri di mim | eu nada tenho a lhi dizer pur que vosmece| quando mi escrevi nada mi diz [...] (JMS-66) 
(39) Estimado querido| Amigo Compadi| pitanga Eu mandol Dez mil Corzeirol pur metodi [.]/s s sim compadi| u simhor sir puder| pargi A [.]| Farncico motal Zacarias Er di oul tar veizi sim Compadi| eu não [...] (AFS-3)

(40) Perzado querido Amigor Conpadi pitanga conpadi / eu ffiquei muito ssaltifeito di saber da soua notiçal Conpadi pitanga eu fiqei Comtemti [.]l du senho ter min a virzado que $\mathrm{A}$ minha Conmadil teivi Cirança empais gaça a nosa senhora dul bom parto Conpadi er u que eu Dezejo i estinmol minha Conmadi nosa senhora li dei saudi A cenhora ial Ceu filinho toudo [.]l quatos ssim Conpadi eul vou [...] (AFS-7)

(41) [... Compadi commo vai u simhorl ir mihas commadi ir us meninol compadi eu estou com muital saldade du $\mathrm{s}$ sinhor compadi eul recibi 3 carta du sinhor compadi| não poso esquecer du sinhor / compadi [.] vanmo pedir Al noso bom Deus que eu vorto A mial terral compadi condo eu Alenbor| du simhor eu firco qauzil choranno di ir Amizadi ir dul noso viver compadi não vail [...] (AFS-13)

(42) [...] sim comade eul estou com coude graçal a meu bom Deus siml eu depois que eu tou ol aqui e Campina el ja Ganhei uu nene sol sim comade deu Lembracal a [.] compade Nerado el a dona maria e tio agustil e a nide mais u espozol e A criançar todás| sim Comade eu mandol esta fotogafia [...] (AOL-72)

Predominam as repetições dos itens senhor/senhora, você, vosmecê, compadre/comadre, com as variações gráficas específicas a cada carta. No último exemplo da lista anterior, retirado da carta 72, há ainda a presença do marcador sim, que também aparece nos exemplos (39) e (40), contribuindo para estabelecer maior ratificação do papel do ouvinte. Para os dados da oralidade, Marcuschi (1996) comenta que essa função interativa, assim como o uso dos marcadores sim, claro, ahã, sei, expressam a ideia de que o outro pode continuar a palavra. No caso dos textos escritos, essas repetições parecem ter o objetivo de envolver o destinatário, atraindo sua atenção, mas confirmando que ele, o remetente, continua com a palavra. Em alguns casos, a forma de tratamento usada sugere uma maior afetividade: 
v. 8 (2)

$267-287$

mai/ago 2018
(43) Querido José Mindes de Almeida| Querido fiquem bastante alege| recebe a Sua carta consigo asim ti amando Querido Ti amol amor?| (AHC-54)

(44) [... ] mia gerida eu ti gero pu diceru gi ti amol Helena eu pecizo de voci mia gerida oli Se eul gezesi ti engana [...] (JMA-64)

(45) minha estimada Amiga i querida comadre| Firmina a deos muita alegria eu tirial si tivessi a certeiza que estas mal notadal linhas hia encontra aminha comadre il Amiga com saudi [...] (JMS-66)

Já nos trechos a seguir, o item lexical repetido é o próprio nome do destinatário, como se o redator objetivasse mantê-lo atento:

(46) [...] Saudasão sim Juão nois Cegemos| Empaz grasa adeus sim Juão eul Comprei 8000 tarefa deterra i umal Comprei uma vaca [.]। Nada mais dei lembransa al Comprade pedro i agusto i atodos| que pergumta pormi Juão eul vou no mes di setembro [...] (GOR-27)

(47) Zezete| O fim desta duai linha e so para dar| ais minha notisia e ão mesmo tempol saber dais sual Zezete nois aqui estanos todos bem/ garsa a Deus.I Zezete manda me dizer como vai todios | air que eu escrivir par dimisio e não| teve reposta todo dia porcura e maol tem manda mi dizer ais novidadel por air. Zezete voce teve novidadel e não mandou mi dizer| foi você e Neraudo que foi ol padrinho de cazamento de Zifirinol si foi manda mi dizer.| Zezete voçe mandou mi perguntar| si eu já tinha mi Operado dais| varis mais não foi a Operei para não ter| mais filho ti asegura que eu já mi al seguri Olha minha filha foil emternada 8 dia mais ja tar boal [...] Zezete eu resebir a tua carta e demoreil de te esquever mais não foi nadal foi falta de disposisãol Zezete nois estamos pensando em/ ir embora $[\ldots]$ (ZLS-70) 
(48) Meu amigo Nerado | Nerado nois aqui estamos todos $\mid$ bem garsa a Deus.| Nerado resebir tua carta vir todol que vinha dizendol Sim Nerado mande mi dize quantol qusta um dia de um tarbalhador [...] (ROM-73)

(49) prezada amiga elena boã tardel como passou daqueli dia paral car passou bem olhe elena eu paseil muito bem e espero que você tambem/ esteja passado Elena vou bem elena| elena aquela converça com seu nomil ja acabou olha as mesma converçal saiu aqui com meu nomi não voul conta porque não tenho tempo porquel quando jose falou de ir eu alembreil di te escrever esta duas linha so paral te fala que eu fique um mui tristil quando eu subi di converça que eul não posso aseita elena termina tel escrevedo com muita saldadi [...] (BMO-90)

Destaca-se a presença do marcador sim também nos exemplos (46) e (48). A rasura que aparece no exemplo (49), em que foi omitido o item elena, e a repetição desse mesmo item em seguida, de forma adjacente (Elena vou bem elenal elena aquela converça) confirma a ideia de um texto que reflete um planejado em tempo real, espontâneo; é uma repetição que ocorre em mudança de linha e sugere o início de um novo tópico, sem perder a interação com o destinatário. Essa repetição adjacente aparece, também, em (50), mas não em final de linha, em que se percebe o próprio ritmo do texto, de modo que, mesmo estando ausentes os sinais de pontuação, o item repetido tem passado reflete uma pausa com uma interrogação:

(50) no momento em quel escrevo quero lhi dizer quel ficamos bem graças a Deus| [.] ia senhora com tem| passado tem passado bem l a qui todos tem saudadel [...] (LM-75)

Em (51), trecho que apresenta um tom mais formal, pois JPC expressa um pedido de casamento, também há repetição:

(51) [...] u fin destal duas linhas vai pidinol Almerinda a cazamentol i eu estimo a saber si el du seu gosto i stimareis | a saber da respostal [...] (JPC-82) 
v. $8(2)$

267-287

mai/ago 2018

Nota-se, nesse caso, que a relação com o outro é mantida com certa polidez, e a repetição de a saber colabora para isso, já que, pelo contexto em que aparece, indica educação e respeito.

\section{Considerações finais}

A presença excessiva da repetição no corpus, essa que é uma estratégia básica de formulação da fala, é um indício de que as cartas dos sertanejos, escritas no século XX, registram uma escrita espontânea, mais próxima da oralidade. Os exemplos analisados permitem constatar que:

a) assim como outras dimensões de inabilidade, a repetição não é determinante na caracterização de uma maior dificuldade com o código escrito; só combinada a outros aspectos é que contribui para indicar um nível de escrita mais inábil. Isso porque há textos que apresentam muitos dados de outros aspectos, como os relacionados à dimensão da escriptualidade (irregularidades na grafia de sílabas complexas com o <r>, por exemplo), mas poucos termos repetidos;

b) por serem adultos em fase de aquisição da escrita, os redatores transferem para o registro escrito mecanismos de coesão e coerência comuns à modalidade oral. Motivadas por diversos fatores, tanto no plano textual como no discursivo, as repetições mais frequentes foram aquelas usadas para estabelecer a coesividade e também as que buscam facilitar a interatividade com o destinatário.

O estudo desse fenômeno é relevante, portanto, para o trabalho com corpora, no âmbito dos estudos sócio-históricos do português brasileiro, auxiliando no reconhecimento de textos de redatores em fase inicial de aquisição da escrita, pois, considerando-se a impossibilidade de acesso à fala dos indivíduos de sincronias passadas, os documentos mais transparentes na escrita, em relação aos dados da oralidade, aqueles produzidos por mãos pouco hábeis em escrita alfabética, tem especial valor, são o material empírico para o estudo dessas sincronias. Nesse mesmo sentido, o trabalho contribui para os estudos da História Social da Cultura Escrita, considerando-se a dificuldade de se encontrar textos que refletem a escrita cotidiana, vernacular, visibilizando as práticas de escrita de pessoas comuns, em determinado espaço/tempo. 


\section{Referências}

ANTUNES, Irandé. Lutar com palavras: coesão e coerência. São Paulo: Parábola Editorial, 2005.

BARBOSA, Afrânio Gonçalves. O controle de marcas de inabilidade na escrita alfabética e a identificação das mãos inábeis em corpora histórico-diacrônicos. Revista da ABRALIN, V.16, n.2, p. 19-43, Jan./Fev./Mar./Abril de 2017. Disponível em: <http://revistas.ufpr.br/abralin/article/view/51997/32039>. Acesso em: 09. Maio. 2017.

DUTRA, Rosália. O falante gramático: introdução à prática do estudo e ensino do português. Campinas, SP: Mercado de Letras, 2003.

FÁVERO, Leonor Lopes et al. Oralidade e escrita: perspectivas para o ensino da língua materna. São Paulo: Cortez, 2012.

MARQUILHAS, Rita. A faculdade das letras: Leitura e escrita em Portugal no séc. XVII. Lisboa: Imprensa Nacional-Casa da Moeda, 2000.

MARQUILHAS, Rita. O preço da ilegibilidade. Nota em defesa das edições interpretativas, seguida de edição de cartas privadas e de cartas testemunhais portuguesas (séc. XVII). In: AGRELO, Ana Isabel Boullón (Ed.). Novi te ex nomin: estudos filolóxicos ofrecidos ao Prof. Dr. Dieter Kremer. A Coruña: Fundación Pedro Barrié de la Maza, 2004. p. 721-747.

MARCUSCHI. Luiz Antônio. A repetição na língua falada como estratégia de formulação textual. In: $\mathrm{KOCH}$, Ingedore G. Villaça (Org.). Gramática do português falado. V. 6. Campinas, SP: Editora da UNICAMP/FAPESP, 1996. p. 95-129.

MATTOS E SILVA, Rosa Virgínia. (Org.). Para a história do português brasileiro: primeiros estudos. t. II. São Paulo: Humanitas/FFLCH/USP/FAPESP, 2001.

SANTIAGO. Huda da Silva. Cartas em Sisal: Riachão do Jacuípe, Conceição do Coité e Ichu (1906-2000): edição fac-similada. In. SANTIAGO, Huda da Silva; CARNEIRO, Zenaide de Oliveira Novais; OLIVEIRA, Klebson (Org.). Volume 3 de Cartas brasileiras (1809-2000): coletânea de fontes para o estudo do português. Feira de Santana: UEFS Editora, 2011. 1 CD-ROM.

SANTIAGO. Huda da Silva. Um estudo do português popular brasileiro em cartas pessoais de "mãos cândidas" do sertão baiano. 2V. Feira de Santana, 2012. Dissertação (Mestrado em Estudos Linguísticos) - Programa de Pósgraduação em Estudos Linguísticos, Universidade Estadual de Feira de Santana, 2012.

TELLES, Célia Marques; LOSE, Alícia Duhá. Escrita e fala: o que ensinam os textos não literários. Línguas e letras, v.11, n. 20, p. 107-132, 2010. Disponível em: <http://e-revista.unioeste.br/index.php/linguaseletras/article/ viewFile/4140/3199>. Acesso em: 26 jun. 2017. 